\title{
Current trends in traffic safety - the need for crossing the borders of disciplines
}

\author{
Claes Tingvall ${ }^{1,2,3}$
}

\author{
${ }^{1}$ Chalmers University of Technology, Sweden \\ ${ }^{2}$ Accident Research Centre, Monash University, Australia \\ ${ }^{3} A F R Y$, Sweden
}

Handling editor \& reviewer: Aliaksei Laureshyn, Lund University, Sweden

Received: 30 April 2021; Accepted: 20 May 2021; Published: 30 June 2021

Just over a year ago, the $3^{\text {rd }}$ Global Ministerial Conference on Road Safety was held in Stockholm (Road Safety Conference, 2020). Since then, the world has experienced a pandemic that hit us all, wherever we are, whatever we do. We have learnt new things, we have understood complex interactions and hopefully we will be handling the next pandemic better. It will be the role of the scientific community to explore, build and test new hypotheses, discuss and propose actions and scope for further research. We know that our processes for building new knowledge by challenging the current wisdom, theory and axioms is working and leads us to the next steps.

Road traffic crashes with serious injuries and deaths has been a pandemic for more than 100 years, constantly ongoing. Our virus is kinetic energy - invisible, mysterious and equally hard to explain to citizens without using true knowledge like the laws of physics. Intuition, gut feeling and populism are our enemies despite a good understanding among researchers.

The ingredients of a successful prevention have been demonstrated during the pandemic. The development of vaccine, treatment and lowering the risk of outbreaks has been extremely fast, and not without real success. But it will probably take many years to understand the most effective components of a society that is well prepared to meet the next pandemic. Is it preparedness to response with lockdowns? Or is it the way the health care for the elderly is organized? Or how quickly new vaccines can be developed? Or is it everything together, in a process where every step is needed to stop the pandemic?

In road safety, we have been successful in developing the vaccines, but slow to implement them in the society. But when in full action, we have demonstrated how well they can function. Roundabouts instead of signalized intersections, seat belts, helmets and electronic stability control are all excellent examples of successful safety treatments. But still, unsafe intersections are being built, cars without basic safety technology are produced and sold and helmets are still not used everywhere. And safety is unequally spread over the world, despite its availability. Almost $90 \%$ of all road deaths occur in low- and middle-income countries, and children are still at high risk in many countries. The understanding, expressed recently by the United Nations General Assembly Resolution 74/299 (UN, 2020), is that the vaccine for road deaths has not been applied where it should be applied. Millions of people are still not getting the vaccine although it has been around for decades.

We can, and often do blame the Governments for not acting, or using wrong and ineffective countermeasures. No doubt, Governments have a role, but it is too easy to blame someone else. 
Maybe we should look more at the role of research, how it is transferred to action and how the knowledge is disseminated through the society. And there is plenty to be quite critical about. Our excellent methods to look at our subject in detail is not enough when we turn to the field of successful implementation. Science does not permeate into practice. We seem to believe that if we deliver the right method, it will be used. If not, we blame the society. But maybe we should be more careful here. Maybe implementation is about what motives the society has, and who would have the strongest interest in making things happen. Sometimes it might be the commercial sector, sometimes not. But what do we deliver in terms of scientific knowledge about how things are being delivered to the society? And how much do we pick up from other sectors and disciplines? Are we aware of the climate change agenda and what this sector does and what mechanisms are used? Or how the investment market deals with sustainability issues? Why do multinational corporations report extensively on climate, health and equity, but not a word about the road safety footprint? The value chains of these corporations run across all nations and are in one way or another involved in every road death - not as a perpetrator, but within their sphere of influence. Why does poor traffic safety not transfer to poor working conditions for those having the road as their working environment? And why is lack of road safety considered to be an adverse effect of mobility that needs to be cost-effective to be dealt with, while the fight against global warming is about existence?

Many of the suggestions to bring safety to the world could be found in the expert group recommendations report published in conjunction with the $3^{\text {rd }}$ Ministerial Conference in 2020 (Trafikverket, 2019). It certainly concerns the scientific community and clearly points to that we are too focused on details, too focused on the inner life of the road safety community and too focused on the traditional methods we use. We have not understood that we are a part of the 2030 agenda along with climate, health and equity. We have not looked at the new instruments we have at hand. And we are not understood by the wider community as we are lousy in bringing science to action.

My answer is that prevention research must be wider than another logistic regression, another human model and another self-driving vehicle. It is about the entire chain from understanding kinetic energy to making the prevention wide-spread, affordable, effective and attractive to the citizens. It is by then we can be proud of being a researcher. But we need ways to get the scientific process scrutinized, discussed and spread, and therefore we need arenas where we can publish. We no doubt need arenas for publication that mirror what the Stockholm Declaration (2020) tells us to do; to be within the family of sustainability, no more and no less! All relevant disciplines must cooperate, not dig deeper wholes but dig longer channels. A publication arena for the whole road safety sector is what we need!

\section{References}

Road Safety Conference (2020) $3^{\text {rd }}$ Global Ministerial Conference on Road Safety: https://www.roadsafetysweden.com (Acc. 20 May 2021)

Stockholm Declaration (2020) Achieving Global Goals 2030. Third Global Ministerial Conference on Road Safety, Stockholm

Trafikverket (2019) Saving Lives Beyond 2020: The Next Steps. Recommendations of the Academic Expert Group for the $3^{\text {rd }}$ Global Ministerial Conference on Road Safety. Commissioned by the Swedish Transport Administration (Trafikverket)

UN (2020) Improving global road safety. United Nations General Assembly Resolution 74/299: https://undocs.org/en/A/RES/74/299 


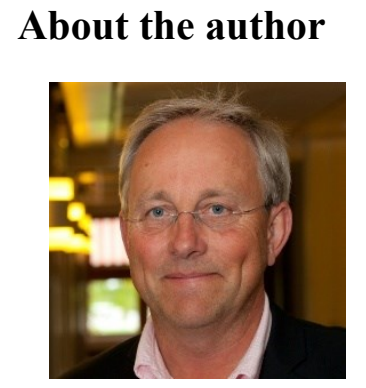

Professor Claes Tingvall is retired from the Swedish Transport Administration where he was Director of Traffic Safety until 2015. Claes Tingvall has a PhD from Karolinska Institute in Sweden (DrMedSc) and a DSc h.c. from Emory University in Atlanta. He is an Adjunct Professor at Chalmers University of Technology, Sweden, as well as Monash University Accident Research Centre, Australia. Claes Tingvall was instrumental in developing Vision Zero from the very beginning. He has published in injury epidemiology, safety rating and safety management.

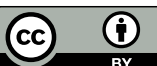

All contents are licensed under the Creative Commons Attribution 4.0 International License. 